\title{
Genome-Wide Identification and Expression Analysis of AP2/EREBP Transcription Factors in Litchi (Litchi chinensis Sonn.)
}

\author{
Jia-li Men ${ }^{1,2,3} \cdot$ Fang $\mathrm{Li}^{2,3} \cdot$ Jin-hua Sun ${ }^{2,3} \cdot$ Guo Wang ${ }^{2,3} \cdot$ Huan-ling $\mathrm{Li}^{2,3} \cdot$ Shu-jun Wang ${ }^{2,3} \cdot$ Yun Xu $\cdot$ Jia-bao Wang ${ }^{2,3}$
}

Received: 13 April 2021 / Accepted: 20 July 2021 / Published online: 10 September 2021

(C) The Author(s) 2021

\begin{abstract}
APETALA2/ethylene response element binding proteins (AP2/EREBP) are a vital type of TF involved in plant organ development and embryogenesis. In this study we identified 202 Litchi AP2/EREBP TFs from the litchi genome. They were classified into four subfamilies by phylogenetic clustering, including AP2s (20), ERFs (112), DREBs (64), and RAVs (6). Analysis of conserved domains, motifs, gene structure, and genome localization were carried out to investigate the evolutionary features of litchi AP2/EREBPs. Over 35\% of DREBs and ERFs involved in the expansion of litchi AP2/EREBPs resulted from tandem duplication. The majority of genomic organizations were conservative, except those of the AP2 subfamily, which had no intron and contained less conservative motif numbers. The expression profiles of litchi AP2/EREBPs in ten tissues were investigated using RNA-Seq data and fifty-nine showed tissue-specific expressions. Their expression patterns were confirmed by qRT-PCR with eight tissues-specificity genes. Six genes related to embryogenesis were identified using the map of orthologous gene interaction between Arabidopsis and litchi. This paper is a comprehensive report on the characteristics of the litchi AP2/EREBP gene superfamily. It will serve to further explore the regulatory mechanisms of AP2/EREBP TFs in the litchi somatic embryogenesis and provide information for litchi molecular breeding.
\end{abstract}

Keywords Litchi chinensis · AP2/EREBP transcription factors · Bioinformatics · Expression pattern · Somatic embryogenesis

\section{Introduction}

Litchi, belonging to Sapindaceae Juss., is a famous and important subtropical fruit tree. In 2018, the litchi planting area totaled 553 thousand hectares and 3 million tons were produced in China (Chen et al. 2019). Due to the rapid

Communicated by: Elliosha Hajari

Yun $\mathrm{Xu}$ and Jia-bao Wang are co-corresponding authors.

Yun $\mathrm{Xu}$

xuyun2000513@126.com

$\triangle$ Jia-bao Wang

fdabo@163.com

1 School of Life Sciences, Hainan University, Hainan 570203 Haikou, P.R. China

2 Environment and Plant Protection Institute, Chinese Academy of Tropical Agriculture Sciences, Haikou, Hainan 570100, P.R. China

3 Danzhou Scientific Observing and Experimental Station of Agro-Environment, Ministry of Agriculture and Rural Affairs, Danzhou, Hainan 571737, P.R. China development of the litchi industry, many problems have arisen that have significantly restricted the further growth and cost-efficiency of the litchi industry. Most litchi varieties are prone to low fruit setting, severe fruit abscission, uneven coloring of the pericarp at fruit ripeness, and a short shelflife due to rapid postharvest browning. Furthermore, diseases caused by Peronophythora litchii and Colletotrichum gloeosporioides and pests such as Conopomorpha sinensis reduce the production and quality of fruit. Breeding new varieties through molecular breeding to improve unfavorable traits is the primary strategy by which producers cope with these limiting factors, and somatic embryogenesis is one of the key steps in the process of molecular breeding. Therefore, it is of significant importance to investigate the key gene controlling organ growth and somatic embryogenesis and the molecular mechanism determining the development of litchi characteristics in order to provide a basis for breeding.

The AP2/ERERFP TF superfamily is one of the largest TF families in plants and is widely expressed throughout the life of the plant. According to the number and type of conserved domains, the superfamily can be roughly divided into 
four subfamilies: APETALA2 (AP2), dehydration-responsive element binding protein (DREB), ethylene-responsive factor (ERF), and Related to ABI3/VP1 (RAV) (Sakuma et al. 2002; Nakano et al. 2006). The AP2 subfamily members contain a pair of identical AP2/EREBP domains; ERF and DREB protein sequences have only one AP2/EREBP domain; and RAVs include one AP2/EREBP domain and one B3 domain. Due to the differences in amino acid sequences, the TFs of each subfamily are quite different from the specificity site of DNA. In general, $\mathrm{AP} 2 \mathrm{~s}$ bind to the genes containing $\mathrm{GCAC}(\mathrm{A} / \mathrm{G})$ $\mathrm{N}(\mathrm{A} / \mathrm{T}) \mathrm{TCCC}(\mathrm{A} / \mathrm{G}) \mathrm{ANG}(\mathrm{C} / \mathrm{T})$ elements and are involved in organ growth and development, such as in flowering, embryogenesis, and seed development (Licausi et al. 2010). DREBs specifically bind with the A/GCCGAC elements and ERFs combine with AGCCGCC of the genes, are involved in the transcriptional regulation of fruit ripening and senescence (Fan et al. 2015). RAV members, such as pepper CARAV1 (Jiang et al. 1996), connect with the CAACA and CACCTG nucleotide sequences to activate the downstream reporter genes with biological functions and are considered to be negative regulators of plant development and defense (Giri et al. 2014).

With the cost of gene sequencing decreasing year by year, the AP2/EREBP gene family has been widely identified and analyzed at the genome-wide level in many plant species including Brassica napus (Song et al. 2016), cotton (Liu and Zhang 2017), pear (Li et al. 2018), and pepper (Jin et al. 2018). To the best of our knowledge, there have been no comprehensive reports on the litchi AP2/EREBP superfamily. In the present study, we performed bioinformatics analyses to study the phylogenetic relationship, gene structure, chromosome localization, gene expression pattern, and interaction network of litchi AP2/EREBPs. The results will help to investigate the functional characterization of AP2/EREBP genes and boost the advancement of litchi breeding research.

\section{Materials and Methods}

\section{Sequence Retrieval and Identification of Litchi AP2/ EREBP Transcription Factors}

A total of 64,482 litchi genome annotated genes and protein sequences were downloaded from the litchi genome database. The AP2/EREBP amino acid sequences of Arabidopsis thaliana were downloaded from the Arabidopsis Information Resource (TAIR; http://www.arabidopsis.org/). The information on AP2/ EREBP TFs in each of the species (Klebsormidium flaccidum (Kuetzing) P.C. Silva et al., Bathycoccus prasinos W. Eikrem \& J. Throndsen., Auxenochlorella protothecoides (Krueger) Kalina \& M. Puncoch., Marchantia polymorpha L., Selaginella moellendorffii Hieron., Pinus taeda L., Picea glauca (Moench) Voss., Amborella trichopoda Baill., Brachypodium Distachyon L., Oryza sativa L., Ricinus communis L., Vitis vinifera L.,
Pyrus, Daucus carota L.) was obtained from PlantTFDB (http:// planttfdb.cbi.pku.edu.cn/).

The AP2 hidden Markov model (HMM) file corresponding to the AP2/EREBP domain (PF00847) was acquired from the Pfam protein family database (http://pfam.xfam.org/), and the proteins downloaded from the litchi genome database were searched using the HMMER 3.0 program with the default parameters (Finn et al. 2011). To avoid omissions, the core sequences of the Arabidopsis thaliana AP2/EREBP conserved domain (YRGVRQRNSGKWVCELREPNKKTRIWLGTFQTAEMAARAHDVAAIALRGRSACLNFA) also served as a probe to match with the litchi protein sequences by BLASTP searching. We then synthesized the two search results. SMART (http://smart.embl-heidelberg.de/) and Pfam (http://pfam.xfam. org/) were used to determine whether the search results contained AP2/EREBP conserved domains. The protein sequences that lacked the core sequences were removed. As a result, a total of 202 litchi AP2/EREBP members were obtained. The cDNA, DNA, and protein sequences of that 202 litchi AP2/EREBP TFs are shown in Text S1, S2, and S3. The 59 pairs alleles list in Table S1.

\section{Litchi AP2/EREBP TF Phylogenetic Tree Analysis}

Multiple sequence alignments of Litchi and Arabidopsis AP2/EREBP proteins were performed using Clustal W (Thompson et al. 1994). IQtree was used for the analysis of phylogenetic and molecular evolutionary relationships (Trifinopoulos et al. 2016). The litchi AP2/EREBP TF phylogenetic tree was constructed using the ML (Maximum Likelihood) method; the tree reliability was set to 1000 bootstrap replicates, and other options were set to default. Tree reliability was evaluated using 1000 bootstrap replicates. Finally, the ITOL website (https://itol.embl.de/) was used to create a graphical representation of the phylogenetic tree.

\section{Analysis of Conserved Sequence Elements and Gene Structure of Litchi AP2/EREBP TFs}

The conserved sequence elements of the litchi AP2/EREBP TFs were analyzed by the online program MEME set to the default parameters (20 maximum motifs, 6 to 200 amino acids in motif width). In addition, an integrative toolkit-TBtool was used to analyze the gene structure by comparing the mRNA with the corresponding genome sequence using the secondary program 'GXF Re-build from sequences'. The resulting two graphs were combined into one using another secondary parameter, 'Amazing optional gene viewer' (Chen et al. 2020).

\section{AP2/EREBP Gene Mapping in the Litchi Genome}

The chromosome location information of 202 AP2/EREBP $\mathrm{TF}$ family genes was downloaded from our laboratory 
database (Table S2). The MapChart 2.32 tool was used to locate the litchi genome-wide AP2/EREBP TFs and create a map. Chr N (N is the chromosome number, 1-15) indicated that the sequence was located on the corresponding chromosome.

\section{Analysis of the Tissue-Specific Expression Patterns of Litchi AP2/EREBP Genes}

The RNA-seq data of litchi AP2/EREBP genes were measured by our research group (Table S3), and then used to detect their expression patterns in 10 tissues, i.e., the roots of one-year-old seedlings, leaves from spring and autumn shoots, female and male flowers, pericarp, pulp, seeds, callus, and somatic embryos. These analyses were performed using hierarchical clustering (Corpet 1988). Reads Per Kilobase per Million mapped reads (RPKM) values for each gene in all tissues were normalized by $\log 2$, and a heat map was created using ImageGP.

\section{Plant Materials and Verifying the Gene Expression by qRT-PCR}

Eight AP2/EREBP genes were randomly selected to confirm their expression pattern in 10 plant samples. The samples were collected from the litchi cultivar "Feizixiao". The mature leaves of spring and autumn shoots were collected in April and October, respectively. Semi-opened female and male flowers were collected in March. The white roots were collected from the seedlings obtained by air layering. Pericarp, pulp, and seeds were separated from the mature fruit. These samples were all taken from the Experiment Station of Hainan Academy of Agricultural Sciences located at Yongfa, Haikou. The callus and somatic embryo were induced according to the method described by Wang (Wang 2013) and collected carefully to avoid contaminating the medium. All samples were rinsed, immediately frozen in liquid nitrogen, and stored at $-80^{\circ} \mathrm{C}$.

Total RNA was isolated using a Quick RNA isolation kit (Huayueyang Biotechnology Co. Ltd., China) following the manufacturer's instructions. The quality and purity of the RNA were measured by the OD260/OD280 absorption ratio (1.9-2.0) and the OD260/OD230 absorption ratio (>2.0), and the integrity of RNA were identified by electrophoresis in a $1.0 \%$ agarose gel. A spectrophotometer (NanoDrop 2000c, Thermo Fisher USA) was used to measure RNA concentrations (Lata et al. 2010). Approximately $1 \mu \mathrm{g}$ of total RNA, $100 \mu \mathrm{M}$ Oligo (dT) primer, 20 U RiboLock RNase Inhibitor, 200 U Reverted Reverse Transcriptase (Thermo Fisher Scientific, USA), and 5X Reaction Buffer were used to synthesize first-strand cDNA within a $20 \mu \mathrm{l}$ reaction buffer following the manufacturer's instructions. Quantitative real-time PCR (qRT-PCR) with 96 plates was conducted using SYBR Premix ExTaq II (TliRNaseH Plus) on a QuantStudio 6 Flex. The final reaction volume of qRT-PCR was $20 \mu \mathrm{m}$ and the kind of plates we used was 96 . The final reaction volume of qRT-PCR was $20 \mu \mathrm{Lcontained} 0.4 \mu \mathrm{L}$ of each primer, $5 \mu \mathrm{L}$ of TB Green Premix Ex Taq (Takara, Japan), $2 \mu \mathrm{L}$ of cDNA, and $7.2 \mu \mathrm{L}$ of $\mathrm{ddH}_{2} \mathrm{O}$. The amplification parameters of the reaction system used were as follows: $95^{\circ} \mathrm{C}$ hold for $10 \mathrm{~min}$, followed by 40 cycles at $95^{\circ} \mathrm{C}$ for $30 \mathrm{~s}, 55^{\circ} \mathrm{C}$ for $30 \mathrm{~s}$ and $72{ }^{\circ} \mathrm{C}$ for $30 \mathrm{~s}$, and default settings were used for the melting curve stage. The actin gene acted as an internal reference gene. All reactions were repeated three times for three independent replicates (Kumar et al. 2013). Ct values were measured by QuantStudio ${ }^{\mathrm{TM}}$ realtime PCR software with default settings. The relative expression levels of candidate genes were calculated by the $2^{-\Delta \Delta \mathrm{Ct}}$ method (Livak and Schmittgen 2001). QRT-PCR was used to verify the expression levels of eight AP2/EREBP genes selected from litchi tissues according to the method described by Khaksefidi et al. (Khaksefidi et al. 2015) and Chen et al. (Chen et al. 2012), and each sample was performed with three biological replicates. The primers are listed in Table S4.

\section{The Analysis of AP2/EREBP Protein Interaction Networks}

The networks of protein interactions were established by the STRING website. Based on the search mode 'Multiple Proteins by Sequences' chosen to perform alignment between Litchi and Arabidopsis, Arabidopsis protein sequences with higher bit scores and identity scores were selected to analyze the network of protein-protein interaction. The maximum number of interactors was not greater than 20 . Cytoscape software was used to trim and create a graphic representation of the interaction networks of proteins (Cline et al. 2007).

\section{Results}

\section{Identification and Sequence Alignment of the Litchi AP2/EREBP TFs}

To identify the genes that encode proteins owning the domain and likely domain of AP2/EREBP, we identified 202 members containing AP2 domains including 59 pairs allele by screening the whole litchi genome sequence. By comparing the number of AP2/EREBP domains and phylogenetic relationships (Fig. 1), all of the genes were classified into four subfamilies, i.e., AP2, DREB, ERF, and RAV, according to the phylogenetic analysis on Arabidopsis AP2/EREBP proteins (Sakuma et al. 2002). The AP2 subfamily contained 20 genes that coded proteins containing double AP2/EREBP domains. Six genes encoding proteins that comprised one AP2/EREBP domain and one B3 domain were classified into the RAV subfamily. A total of 176 genes only encoded one single AP2/EREBP domain. These genes were divided into the DREB and ERF subfamilies, which contained 64 and 112 genes, respectively. Both of these subfamilies 
Tree scale: 0.1

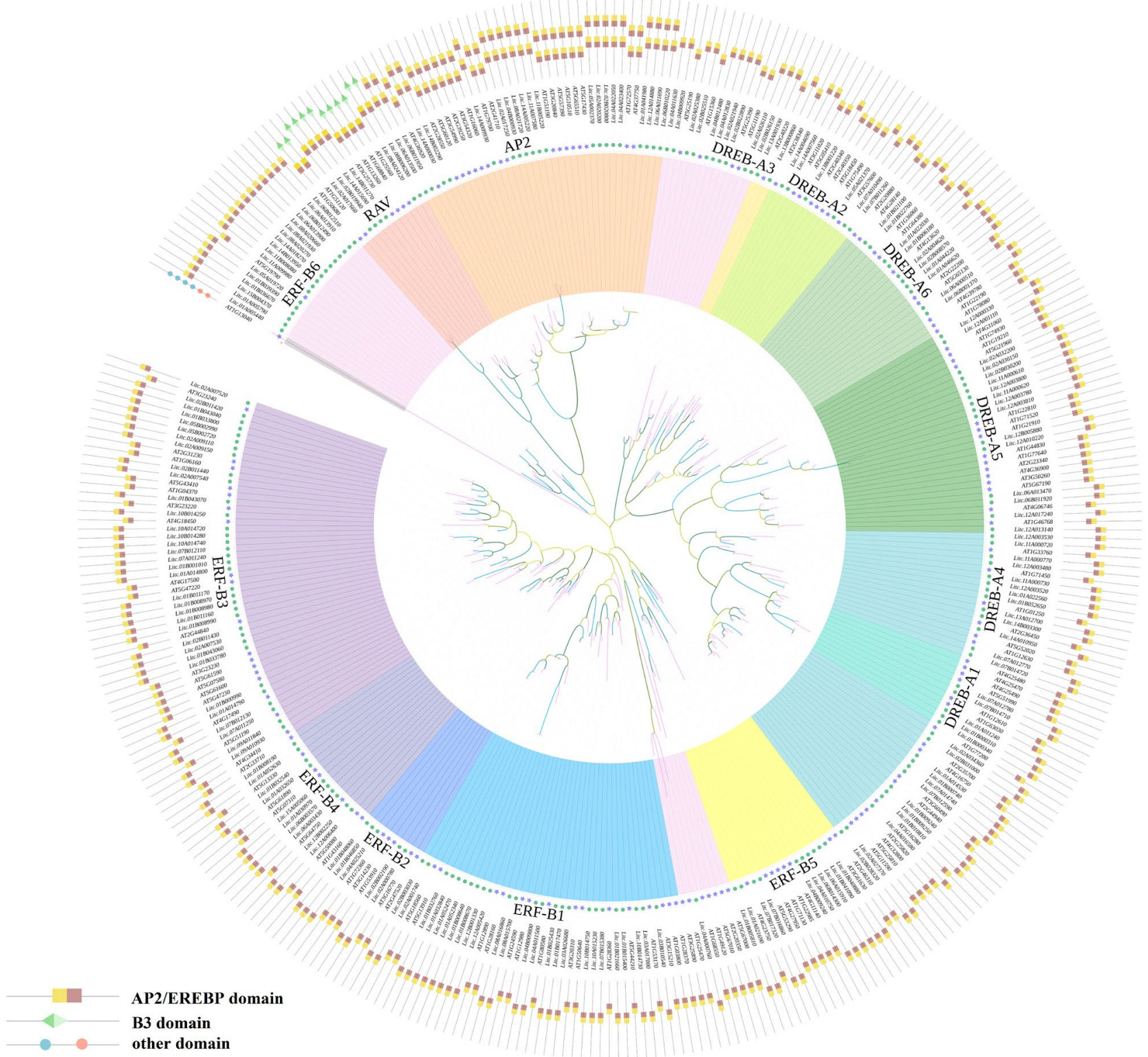

Fig. 1 Phylogenetic analysis of AP2/EREBP proteins between litchi and Arabidopsis. The AP2/EREBP protein sequences of litchi and Arabidopsis were aligned by Clustal W, and the phylogenetic tree was constructed using IQtree by the ML (Maximum Likelihood) method.

could be further subdivided into six groups according to the similarity of amino acid sequences: groups A1-A6 (the DERB subfamily) and groups B1-B6 (the ERF subfamily). No TFs were clustered with Arabidopsis soloist member (At1G13140).

The amino acid residues in the AP2/EREBP domain were aligned for the purpose of further clarifying the differences in the composition of the DERB and ERF subfamilies. As shown in Fig. 2A, 25 conserved amino acid residues were identified in the DREB subfamily, including $2 \mathrm{Y}, 4 \mathrm{G}, 6 \mathrm{R}, 8 \mathrm{R}, 11 \mathrm{G}, 12 \mathrm{~K}$, $13 \mathrm{~W}, 14 \mathrm{~V}, 16 \mathrm{E}, 18 \mathrm{R}, 20 \mathrm{P}, 34 \mathrm{R}, 36 \mathrm{~W}, 37 \mathrm{~L}, 38 \mathrm{G}, 46 \mathrm{~A}, 47 \mathrm{~A}$, 49A, 51D, 53A, 60G, 65A, 67L, $68 \mathrm{~N}$, and 69F. Twenty-five
Based on the phylogenetic relationships, different subgroups were marked with different colors. The numbers and features of conserved domains of AP2/EREBP TFs between Arabidopsis and litchi are exhibited in the outermost part

conserved amino acid residues $(4 \mathrm{G}, 5 \mathrm{~V}, 6 \mathrm{R}, 8 \mathrm{R}, 11 \mathrm{G}, 15 \mathrm{~A}$, 16E, 17I, 34R, $36 \mathrm{~W}, 37 \mathrm{~L}, 38 \mathrm{G}, 39 \mathrm{~T}, 42 \mathrm{~T}, 44 \mathrm{E}, 46 \mathrm{~A}, 47 \mathrm{~A}$, 49A, 50Y, 51D, 53A, 54A, 59G, $68 \mathrm{~N}, 69 \mathrm{~F}$ ) were recognized as in the ERF subfamily (Fig. 2B). Some amino acid residues in the DREBs and ERFs were remarkably different. The DREB subfamily proteins contained $\mathrm{V}$ and $\mathrm{E}(\mathrm{L} / \mathrm{V})$, while the ERF proteins contained A (D) and $\mathrm{D}(\mathrm{H})$ in the $14^{\text {th }}$ and $19^{\text {th }}$ positions. All members of the DREB subfamily and the ERF subfamily contained a WLG conservative motif except one gene of the B6 group (Litc.04A000760), which contained YLG. The characteristics of specific conserved domain regions usually 

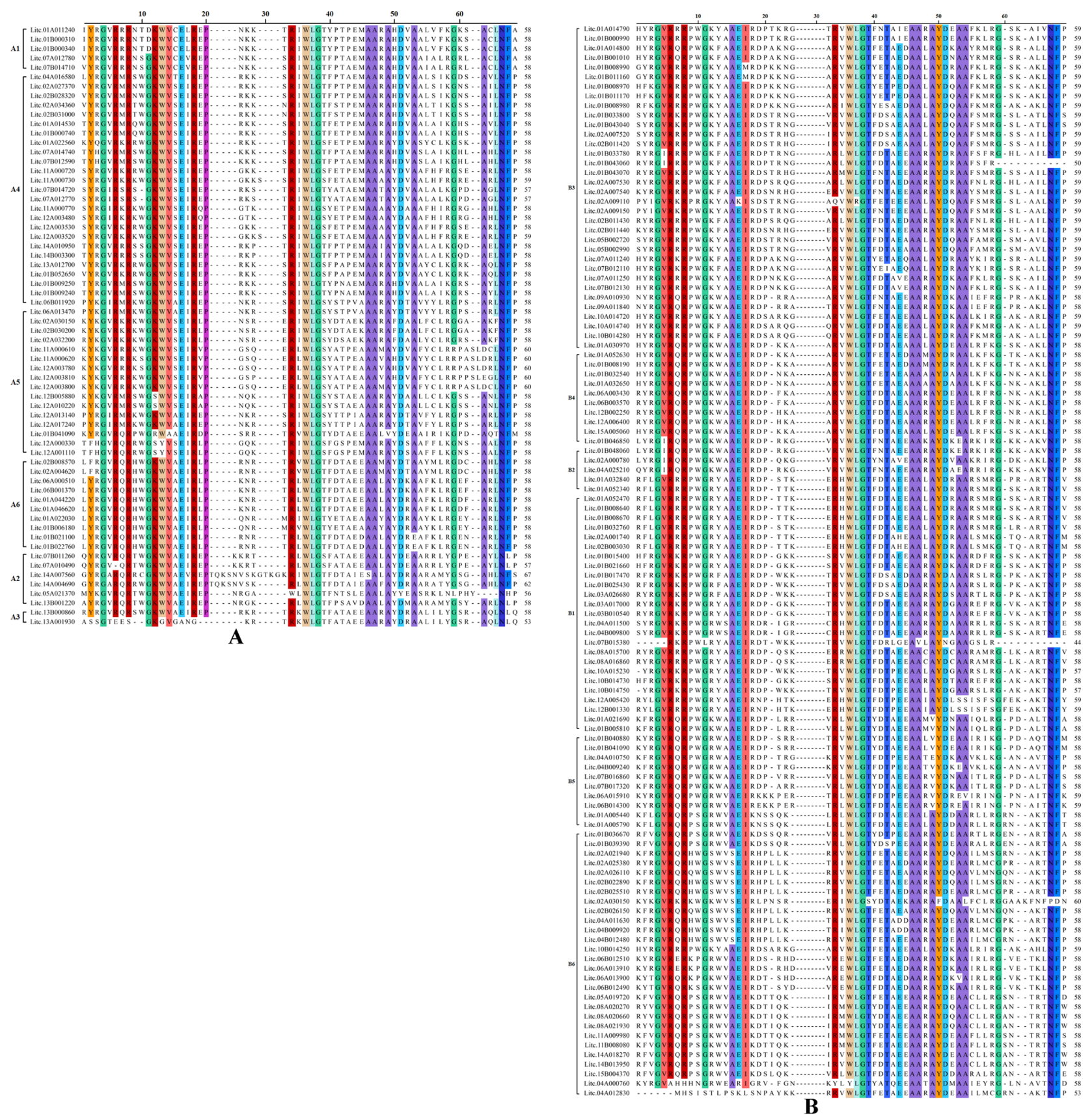

Fig. 2 The analysis of conserved amino acid residues in the AP2/EREBP domain between the DREB (A) and ERF subfamily (B). The different colored background denotes the highly conserved amino acid residues $(>90 \%)$

determined the specific function of the TFs (Xu et al. 2013), which fully embodies the potential leading to functional differences for the TFs of the ERF and DREB subfamilies.

We selected 15 representative plants from the five stages of plant evolution: phycophyta and fungi, bryophytes, pteridophytes, gymnosperms, and angiosperms. Subsequently, we compared the total number and distribution of AP2/EREBP TFs among them. The litchi AP2/EREBP TFs had relatively higher members compared with those in other species (Table 1). Additionally, it was found that the total number of AP2/EREBP TFs increased as plants gradually became more complex. This phenomenon was mainly caused by the expansion of ERF and DREB subfamily members. ERF was the largest subfamily, and the second-largest was DREB, followed by AP2, RAV, and Soloist. However, there were more DREBs than ERFs in Brachypodium distachyon L., which demonstrated that each subfamily of AP2/EREBPs evolved with species-specific characteristics. More interestingly, only AP2 and ERF subfamily members existed in all species. The result showed that AP2s and ERFs are conserved proteins during plant evolution. 


\section{Gene Structure and Conservative Motif Distribution Analysis of AP2/EREBP Genes}

Many specific, important domains or motifs are located outside the AP2/EREBP domain, which is generally linked to transcription regulation and protein-protein interactions (Du et al. 2012). Twenty conserved motifs of the 202 proteins, termed motifs 1 to 20, were found using the MEME tool and confirmed in the Pfam database (Fig. S1). We concluded that the motifs 1, 2, 3, 5,7 , and 8 were located exclusively in the AP2 domain, while motifs 16 and 20, related to the B3 domain, exclusively existed in the RAV subfamily (Fig. 3). Additionally, the motif composition among the factors of the different subfamilies was varied. Motifs 4 and 13 existed in DREB subfamily members, whereas the ERF subfamily contained motifs $15,17,18$, and 19 . Note worthily, the genes having an exclusive motif were evenly clustered in the same group. For instance, motif 19 in protein Litc.01A021690 in the B5 group also occurred in all remaining proteins of the B5 group, i.e., Litc.01B005810, Litc.01B040880, Litc.01B041090, Litc.04A010750, Litc.04B009240, Litc.06A015910, Litc.06B014300, Litc.07B016860, and Litc.07B017320. However, the motif distribution among all these members of the same group was non-uniform. Even so, the motif distribution of most proteins was consistent with phylogenetic clades. In the B3 group, Litc.05B002720 and Litc.05B002990 contained motifs 1, 2, 3, 9, 10, and 14 while Litc.01B033800 and Litc.01B043040 contained motifs $1,2,3,8$, and 14 . Additionally, the quantity of motifs among different groups varied widely. Generally, the motif number of the AP2 subfamily was not less than seven, the RAV subfamily was about six, and the DREB and ERF subfamilies was not more than five.

Gene structure analyses revealed further evidence to support the phylogenetic topology groupings of the litchi AP2/ EREBP gene family. As shown in Fig. 3, most of the ERF (66), DREB (39), and RAV (4) subfamily genes were found
Fig. 3 Conserved motifs and gene structure analysis of litchi AP2/ EREBP genes based on the phylogenetic relationships. A indicates the phylogenetic relationships, $\mathbf{B}$ indicates the conserved motifs, and $\mathbf{C}$ indicates the gene structure analysis. All motifs are represented by the numbers from 1 to 20 , and each color box means different motifs

to be intronless. By comparison, the AP2 genes contained introns ranging from 3 to 10 , with an average of 7.42 , which far outweighed the other subfamilies. The highly diverse gene structure implied that the litchi genome might have undergone tremendous differentiation during production and duplication.

\section{Chromosome Distribution of the AP2/EREBP Family TFs}

The 202 genes were distributed unevenly among the 15 chromosomes (Fig. 4). Chromosomes 9 and 15 contained two AP2/EREBP genes, followed by chromosome 3 (3 genes), chromosome 13 (4), chromosome 5 (5), chromosome 10 (7), chromosome 8 (8), and chromosome 11 (9). The two chromosomes containing the most AP2/EREBP genes were chromosomes 1 and 2, with 56 and 32 genes, respectively, mainly consisting of DREB and ERF subfamily genes. The genes in the B3 group accounted for $25.00 \%$ and $23.52 \%$ of the total genes on chromosome 1 and 2, respectively. This feature was even more distinct in chromosome 12, where genes in group A5 accounted for over 50\% of the total AP2/EREBP genes.

According to Holub's description (Holub 2001), a gene cluster is a region that contains at least three genes within $200 \mathrm{~kb}$ or less. Based on this criterion, we defined nine gene clusters, seven of which had three genes. The other two gene clusters had five and four genes, located on Chromosomes 1 and 2, respectively. However, if we relaxed the standards with two genes in a cluster, 39\% of ERF and DREB members
Table 1 Summary of the total number and distribution of AP2/ EREBP TFs among 15 different species

\begin{tabular}{llllllll}
\hline Plant & Taxonomy & AP2 & ERF & DREB & RAV & Soloist & Total \\
\hline Klebsormidium flaccidum & Charophyta & 3 & 4 & 0 & 1 & 0 & 8 \\
Bathycoccus prasinos & Chlorophytae & 4 & 2 & 0 & 0 & 0 & 6 \\
Auxenochlorella protothecoides & Chlorophytae & 8 & 4 & 0 & 0 & 0 & 12 \\
Marchantia polymorpha & Marchantiophyta & 4 & 20 & 3 & 2 & 0 & 29 \\
Selaginella moellendorffii & Lycopodiophyta & 25 & 44 & 23 & 3 & 3 & 98 \\
Pinus taeda L & Coniferophyta & 4 & 34 & 0 & 0 & 0 & 38 \\
Picea glauca (Moench) Voss & Coniferophyta & 6 & 38 & 0 & 0 & 0 & 44 \\
Amborella trichopoda & Basal Magnoliophyta & 11 & 36 & 24 & 1 & 1 & 73 \\
Brachypodium Distachyon L & Monocots & 23 & 57 & 65 & 4 & 0 & 149 \\
Oryza sativa L & Monocots & 26 & 79 & 52 & 7 & 0 & 164 \\
Ricinus communis L & Eudicots & 19 & 56 & 34 & 4 & 1 & 114 \\
Vitis vinifera L & Eudicots & 20 & 82 & 40 & 6 & 1 & 149 \\
Pyrus & Eudicots & 26 & 101 & 53 & 9 & 1 & 191 \\
Litchi chinensis Sonn & Eudicots & 20 & 112 & 64 & 6 & 0 & 202 \\
Daucus carota L & Eudicots & 38 & 145 & 69 & 12 & 3 & 267 \\
\hline
\end{tabular}




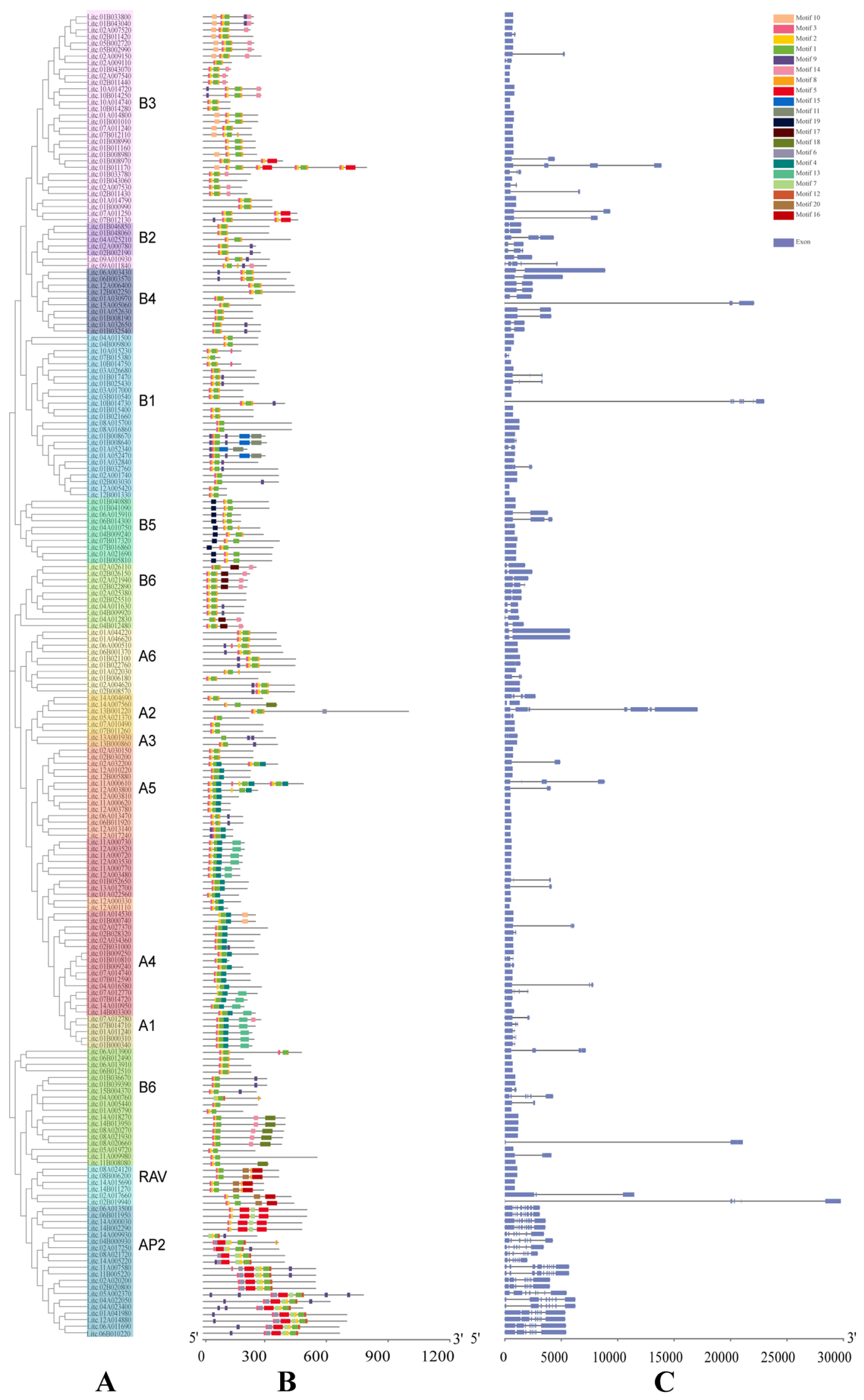


occurred in one cluster, while no noticeable change was seen in the AP2 and RAV members. Gene clusters can be produced by tandem duplication (Reams and Neidle 2004). In the present study, a total of $34.4 \%$ of litchi DREB genes and $44.6 \%$ ERF genes were the results of tandem duplication events.

\section{Expression Profiles of Litchi AP2/EREBP Genes in Different Tissues}

Expression profiling analysis of a gene family can provide references regarding their functions. The expression patterns of litchi AP2/EREBP genes are displayed in Fig. 5A-C. Among all the AP2/EREBP genes, approximately 24 genes that did not express in all the 10 tissues were identified, indicating that they might be associated with other organ development. About 59 genes presented especially high expression in at least one tissue, including nine AP2 subfamily genes, 29 DREB subfamily genes, 19 ERF subfamily genes, and two RAV subfamily genes. In general, gene expression patterns were almost conserved within subfamilies, although expression levels of
Fig. 5 The expression profile of litchi AP2/EREBPs in 10 tissues. (A) (B) and (C) indicate the AP2 and RAV family, DREB family, and ERF family, respectively. The expression values of genes were obtained by RNA-seqs from 10 tissues, i.e., one-year-old "Feizixiao" litchi roots, spring and autumn shoots, female and male flowers, pericarp, pulp, seeds, callus, and somatic embryos. The color scale at the right corresponds to RPKM and was normalized by log2. Red signifies a high expression level, white signifies a medium level, and blue signifies a low level. The differently colored bars at the top represent different tissues. The differently colored strips on the left represent different subfamilies and subgroups of AP2/EREBP genes in litchi

particular members varied from tissue to tissue. For example, the genes specifically expressed in the callus, somatic embryos, and seeds existed only in the AP2 subfamily (Fig. 5A), suggesting that the AP2 subfamily genes might be involved in the process of plant embryo development. The majority of DREB and ERF subfamily genes exhibited different degrees of expression in almost all tissues (Fig. 5B, C). Such a wide range of expression patterns indicated that these genes might be widely involved in regulating the whole life cycle of litchi.

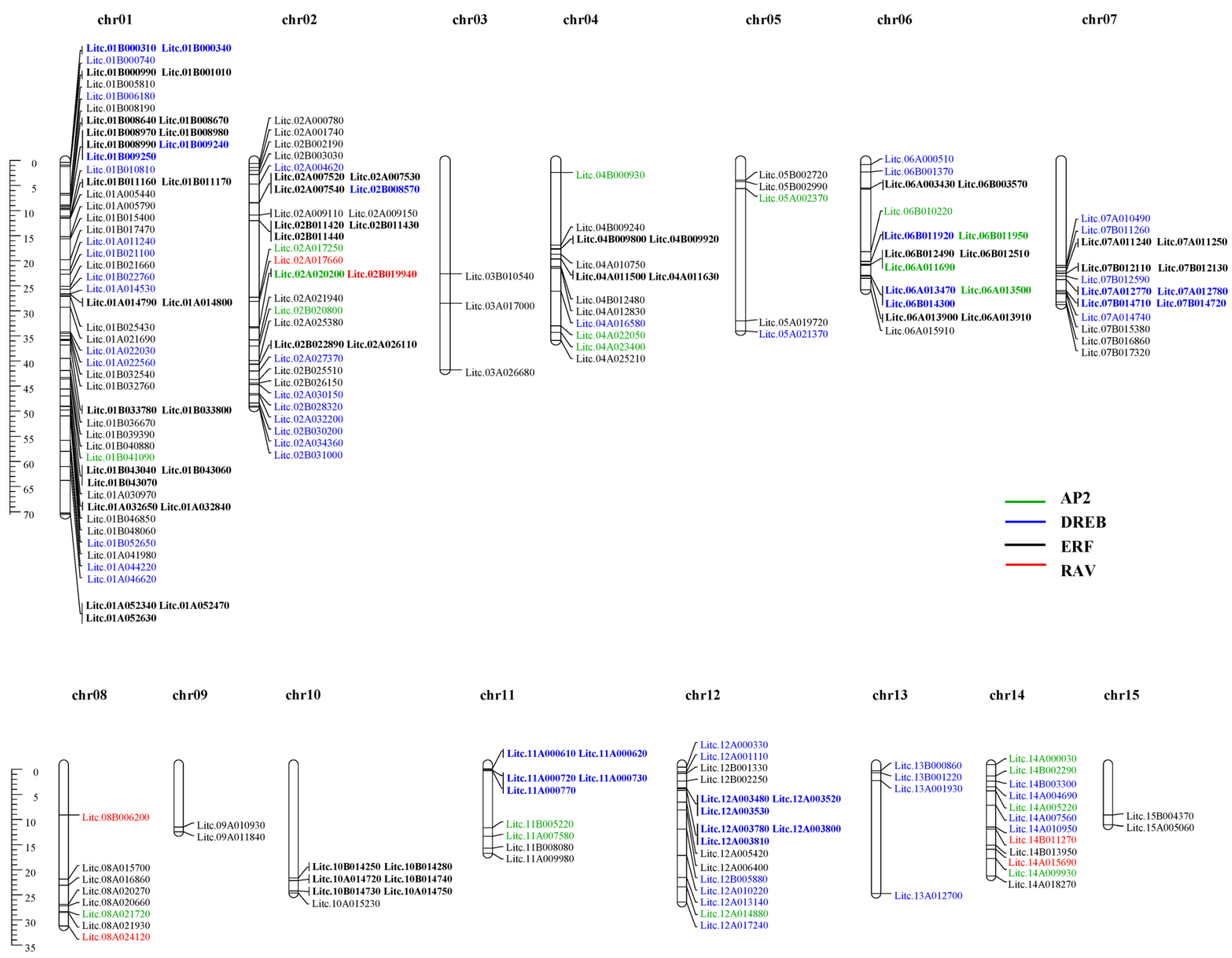

Fig. 4 Mapping of litchi AP2/EREBP genes. The Chr number is indicated at the top of each chromosome. The genes of different subfamilies are displayed with different colors. Scale is in megabases $(\mathrm{Mb})$ 

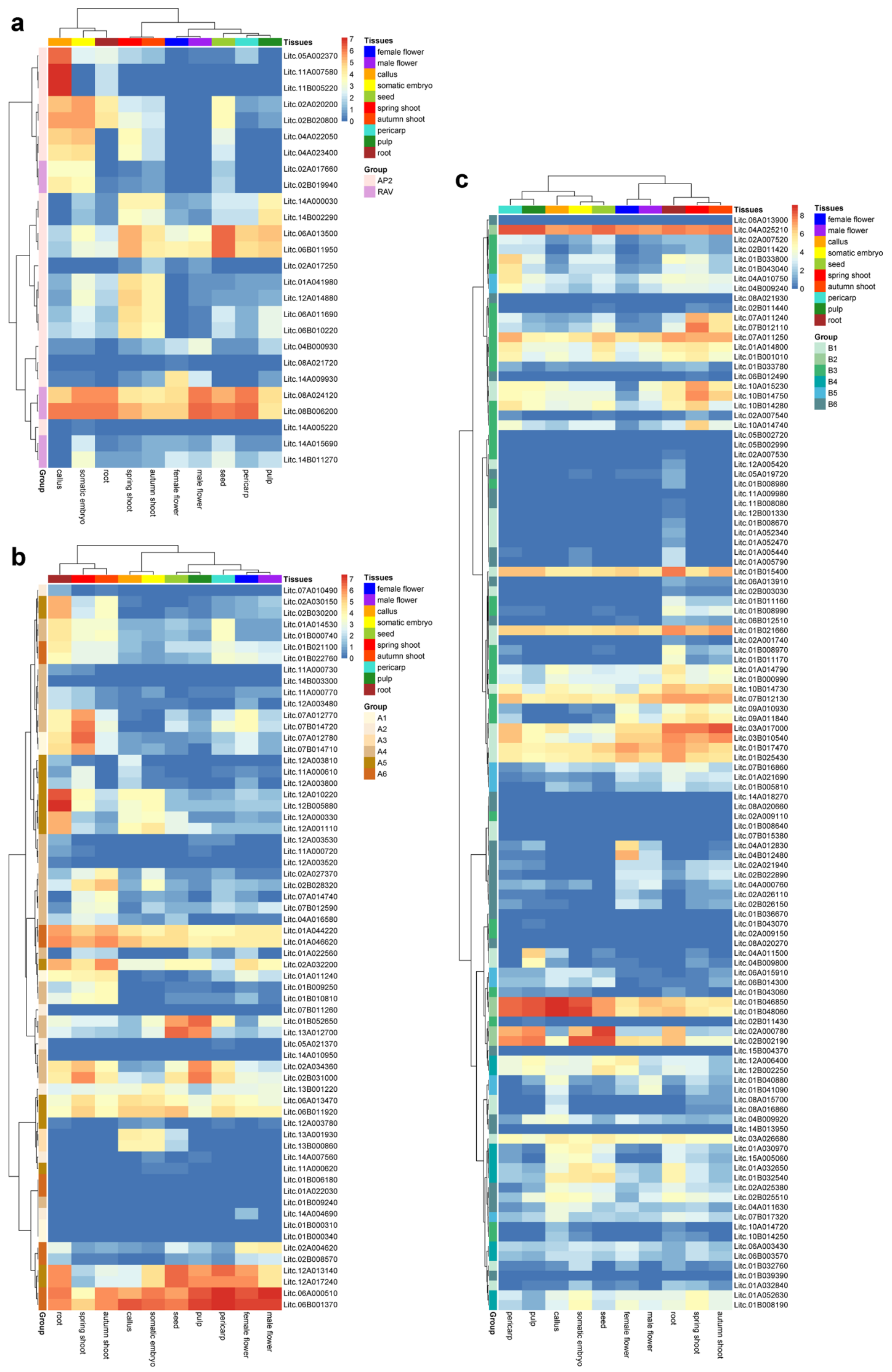
390

Tropical Plant Biology (2021) 14:381-395

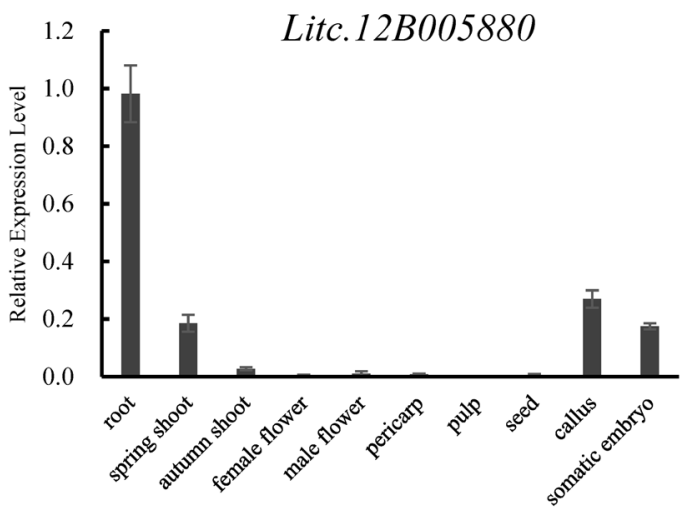

Litc.07B014710
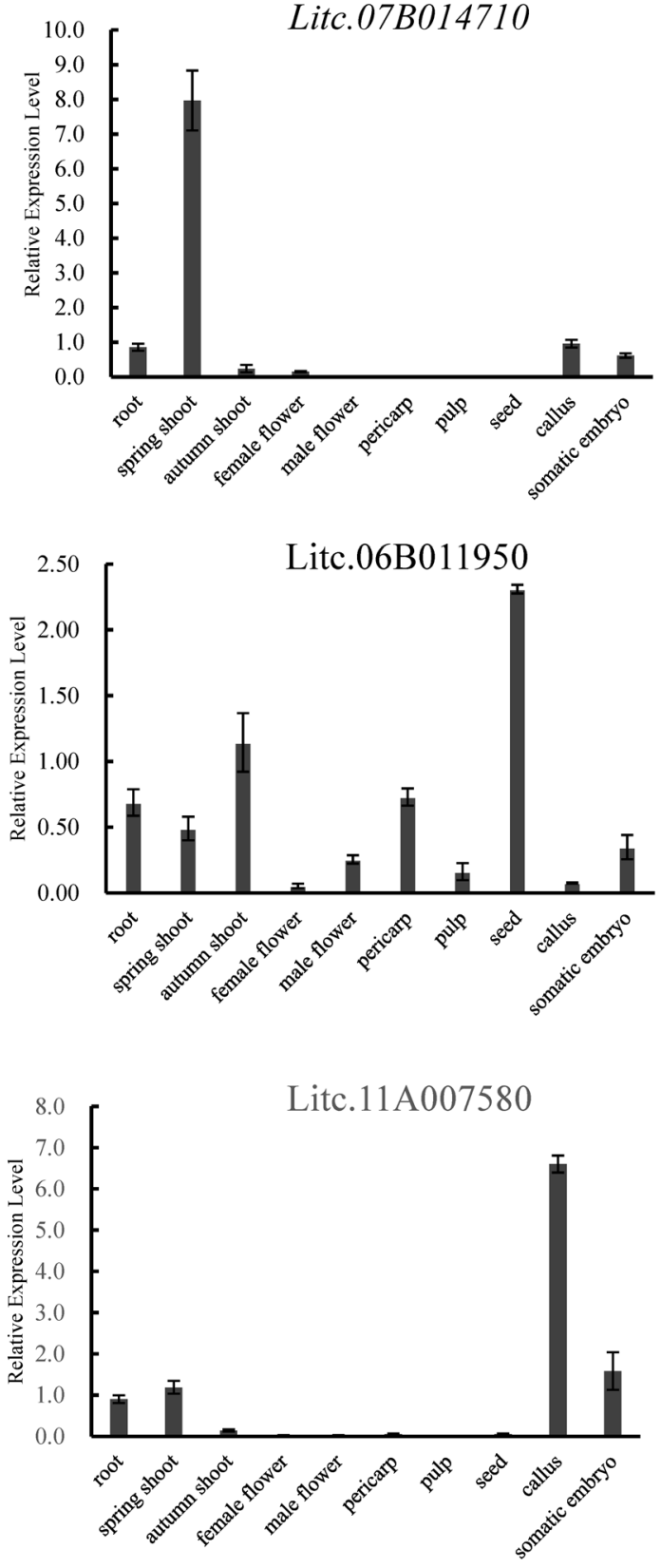

Litc.07A012780

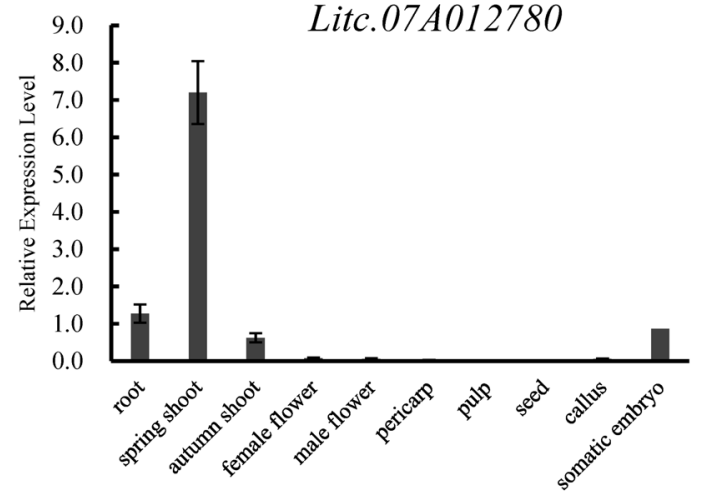

Litc. $13 \mathrm{~A} 012700$
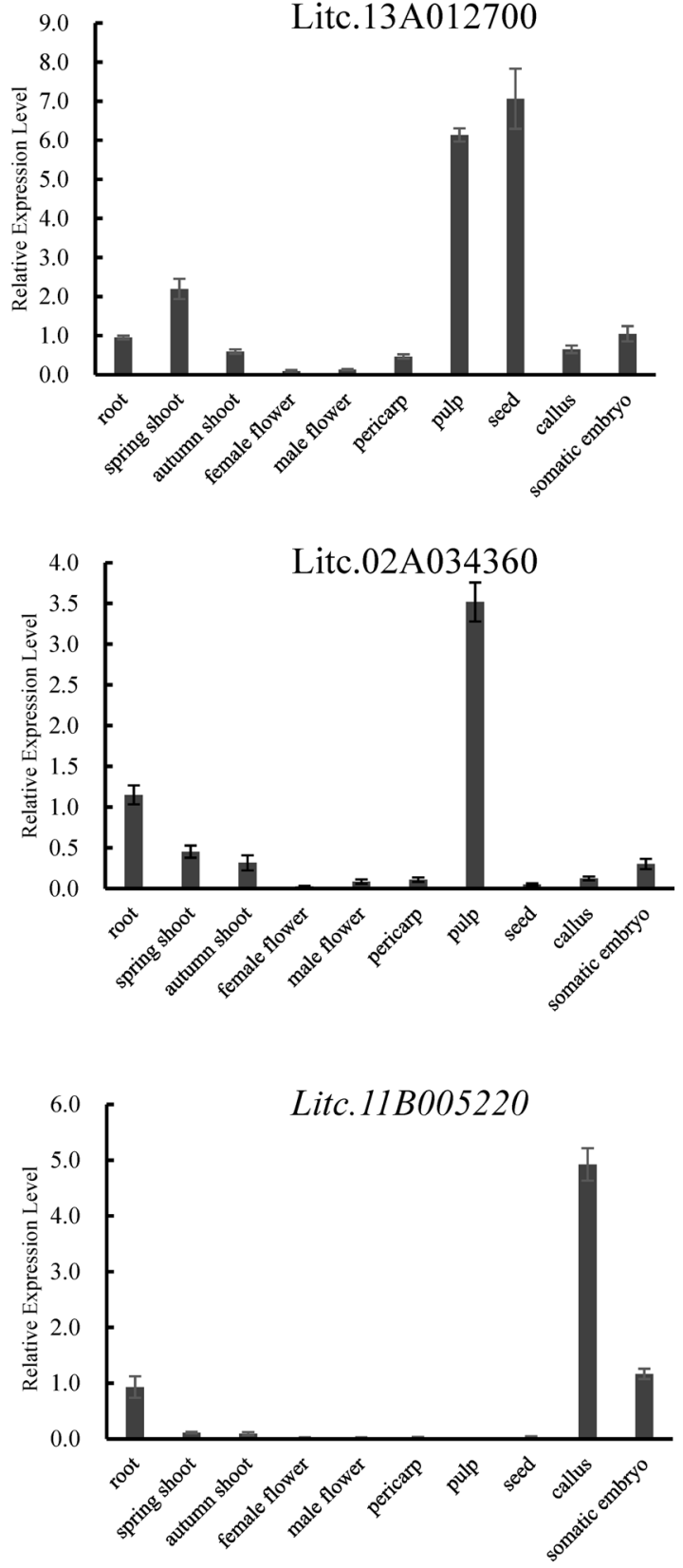

Springer 
४Fig. 6 Relative expression levels of eight genes in 10 tissues. qRTPCR analysis measured the expression levels of eight genes in 10 tissues. The x-axis represents the eight tissues of "Feizixiao", (roots, spring and autumn shoots, female and male flowers, pericarp, pulp, seeds, callus, and somatic embryos). The y-axis represents the relative expression levels of the genes. Data are shown as mean \pm SD from three replications

The RAV subfamily had only six members, but two members had a high expression level in all tissues (Fig. 5A), indicating that the RAV subfamily might play a vital role in cooperating with other TFs during plant development.

We also observed that genes with similar expression patterns shared closer physical positions than other genes contained in the same chromosome. For instance, seven genes of the ERF were subfamily located in chromosome 7, among which two pairs of genes, Litc.07A12770, Litc.07A12780 and Litc.07B14710, Litc.07B14720, had distances of nearly $11.8 \mathrm{~kb}$ and $13.6 \mathrm{~kb}$, respectively. The position distances between these two pairs of genes and the other three genes and distances among the other three genes were more than $400 \mathrm{~kb}$. Both of the two pairs of genes had higher expression in the spring shoots. Among the other three genes, Litc.07A010490 showed lower expression in all tissues while Litc.07B012590 and Litc.07A014740 showed higher expression in autumn shoots.
To further explore the reliability of our functional clustering analysis, 17 genes were randomly selected for qRT-PCR analysis. Among them, Litc.12B005880 exhibited root-specific expression, Litc.07A012780 and Litc.07B014710 exhibited spring shoot-specific expression, Litc.06B011950 and Litc.13A012700 exhibited seed-specific expression, Litc.02A034360 exhibited pulp-specific expression, and Litc.11A007580 and Litc.11B005220 exhibited callus-specific expression. The results of qRT-PCR analysis demonstrated the consistency with the transcriptome data (Fig. 6).

\section{Interaction Function Protein Prediction of Transcription Factors AP2/EREBP}

Proteins are responsible for almost all cellular activity in organisms, such as the control of gene transcription, metabolic activities, and environmental responses. Since proteins usually never work in isolation, understanding their role in signaling pathways and finding the downstream regulatory genes is crucial for identifying their functional protein interaction networks. To analyze and predict the functional relationship of two hundred and two litchi AP2/EREBP proteins, we performed the database of interaction function protein prediction using String web (Fig. 7). The model plant

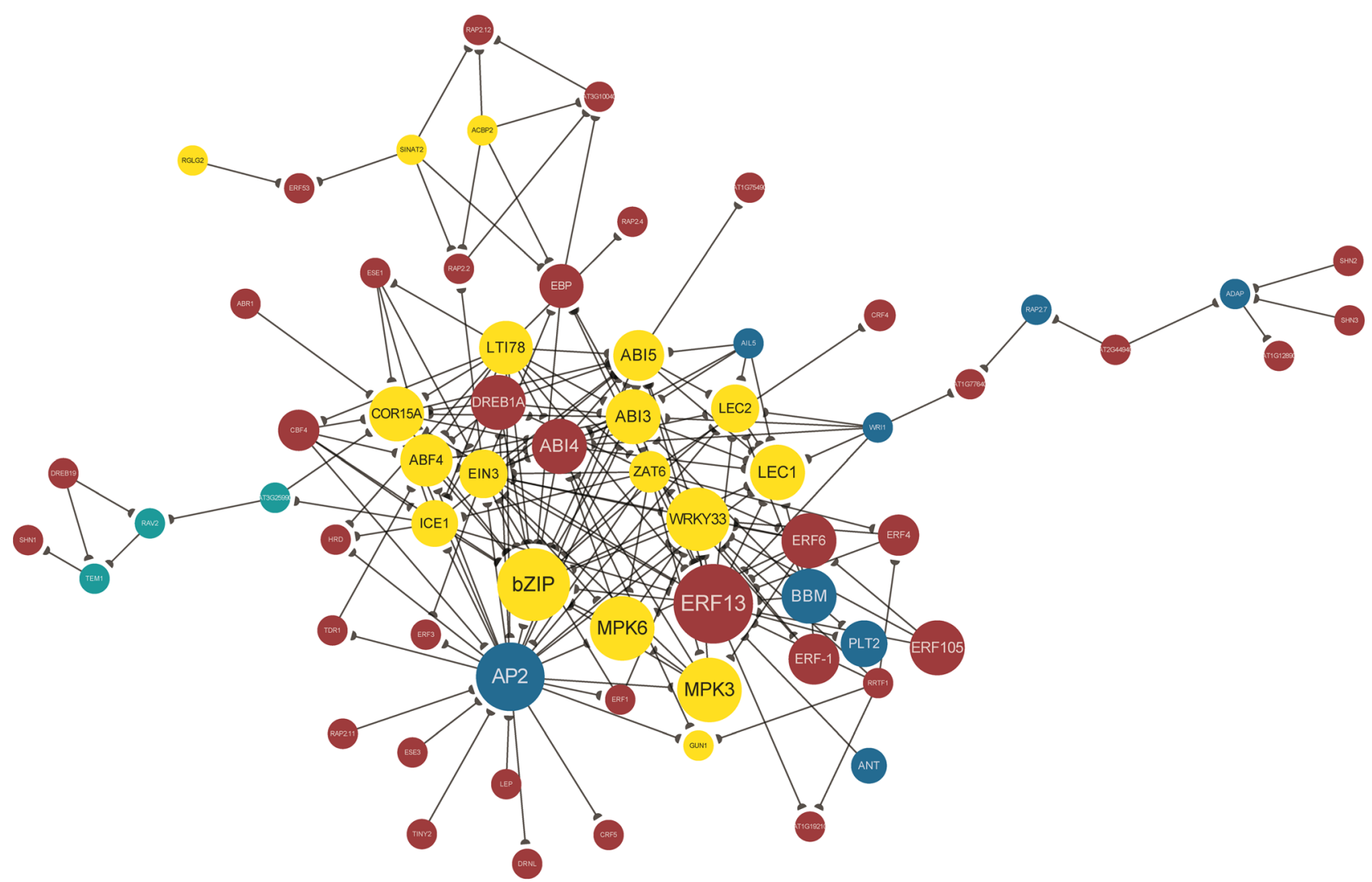

Fig. 7 Interaction network of Litchi TFs and related functional proteins in Arabidopsis. The blue represents Arabidopsis AP2 proteins that have higher DNA sequence similarity with litchi AP2 factors.
The green label is the RAV proteins, the red color refers to ERF or DREB proteins, and the yellow color indicates other types of TFs 
Arabidopsis was chosen as a befitting organism option to match with Litchi.

The forecasting results showed that litchi AP2/EREBP TFs were involved in the multitudinous important biological process as a class of receptor proteins (The details are listed in Table S5). For instance, ERF-1-like (Litc.07B012110) and ABI4-like (Litc.13A001930) were involved in the hormonemediated signaling pathway (Ethylene and Abscisic acid). $C B F$ like proteins, like Litc.07A012780 (CBF4) and Litc.07A014720 $(C B F 3)$ responded to drought stress and low-temperature stress. RAV1 (Litc.08A024120) and RAV2 proteins (Litc.08B006200) had negative regulation at the transcription level. AP2-like proteins (Litc.06A013500, Litc.06B011950) promoted the growth of floral meristems. Intriguingly, AP2/EREBP TFs interacted with not only the same subfamily factors but also other family TFs; for example, AP2s worked together with MPK3 and $M P K 6$; and ERF13 had sophisticated interaction functions with ERF105, LEC1, LEC2, bIZP, and WRKY33. Significantly, seven AP2 subfamily proteins had specific expressions in the callus and embryo and were divided into four types: $B B M$, AINTEGUMENTA-like5 (AIL5), PLT2, and AINTEGUMENTA $(A N T)$. All of them, with the exception of ANT, contained two members exhibiting high sequence similarity. Annotation of six of these genes, i.e., Litc.05A002370 and Litc.04A023400 (BBM-like proteins), Litc.02A020200 and Litc.02B020800 (AIL5-like proteins), and Litc.11A007580 and Litc.11B005220 (PLT2-like proteins), indicated that they were involved in embryogenesis and the developmental transition between the embryonic and vegetative phases of the plants.

\section{Discussion}

The adoption of phylogenetic analysis may facilitate the identification of orthologous genes (Dossa et al. 2016). This tactic has been broadly applied for identifying members of AP2/EREBP TFs in many plant species, such as Medicago truncatula and Brassica rapa (Shu et al. 2016). The AP2/ EREBP superfamily is considered to be one of the essential groups of TF families in plants. In the present study, 202 AP2/EREBP family genes were identified in litchi. We compared the AP2/EREBP members from some representative species in the evolution of the Plantae. Terrestrial plants had a higher AP2/EREBP number than aquatic plants. This finding indicated that the number of AP2/EREBPs in these plants expanded through evolution. The widespread presence of AP2/EREBP TFs indicated that they were conserved as essential functional proteins during the course of evolution (Taylor and Raes 2004). The expansion of ERF and DREB subfamily members offered numerous opportunities for plant evolution. In addition, the quantity of AP2/EREBP TFs varied significantly among higher plants. For example, the total AP2/EREBP number in grapes was 149 while it was 202 in litchi. The abundance of TFs may help litchi adapt to thrive in unstable environments.

In brief, TFs functionally result from some important conserved motifs or amino acid residues within conserved domains. It has been proven that the YRG and RAYD elements within the AP2/EREBP domain are related to cisacting element identification and protein-protein interaction (Gou et al. 2020). The conservative amino acid residues $14^{\text {th }}$ and $19^{\text {th }}$ of the AP2/EREBP domain had critical sites for DNA-binding specificity (Sakuma et al. 2002). The $14 \mathrm{~V}(\mathrm{~A} / \mathrm{D})$ and 19E/L/V(D/H) of the litchi AP2/EREBP domain might be a clue to understanding the functional discrepancy between the ERFs and DREBs in litchi and compare the ERFs and DREBs with those of other species. The components of the conserved motifs also differed in litchi TFs. In the current study, motifs $1,2,3,5,7$, and 8 were detected in the AP2/EREBP domain, while 14 conserved motifs (motif 4, 6, and 9-20) were found outside of the AP2/ EREBP domain in litchi. Most of these conserved motifs represented a group-specific distribution pattern. AP2 family members were higher than other subfamilies in both the numbers and categories of motifs. The amount of conversative motifs in AP2/EREBP TFs of litchi was also more than that in lower plants. For example, only 11 motifs have been identified in AP2/EREBP TFs of desert moss (Syntrichia caninervis) ( $\mathrm{Li}$ et al. 2017).

Some reports have stated that the intron number and their distribution were associated with the evolution of high plants (Hu and Liu 2011). For example, 61.7\% of ERF subfamily members contained more than one intron in moss (Physcomitrella patens), which was remarkably higher than in litchi (40.0\% ERFs) (Tang et al. 2016). The DREBs (58.8\%) and RAVs $(60 \%)$ of litchi were found to be intronless. However, the quantity of introns for each AP2 subfamily member was far beyond that of the ERFs, DREBs, and RAVs. By combining the genes' structural and motif constituent divergence among species or subfamilies, we can speculate that the litchi AP2/EREBP genome has undergone tremendous differentiation during its formation and evolution and that genes of different subfamilies have specific defined roles.

In many plants, tandem duplication has been proven to be a major force in expanding the AP2/EREBP family and is the main reason that gene clusters are produced, such as in Brachypodium distachyon (Chen et al. 2016) and cotton (Liu and Zhang 2017). As illustrated in Fig. 3, the 202 TFs were unevenly distributed across 15 chromosomes, generating 32 gene clusters under relatively relaxed criteria. About $34.4 \%$ of litchi DREB genes and $44.6 \%$ of litchi ERF genes occurred in gene clusters. Surprisingly, no gene clusters were identified in the AP2 and RAV subfamilies either in the relatively stringent or loose criteria, which implied the AP2s and RAVs were comparatively conservative in the process of litchi AP2/EREBP evolution. Additionally, the number of 
gene clusters was about one and a half times more than that of foxtail millet (Lata et al. 2014), barley (Guo et al. 2016), and pepper (Jin et al. 2018). This indicates that more litchi AP2/EREBP genes experience tandem duplication events and produce more duplication genes. This evidence supports the supposition that the gene function of some litchi AP2/ EREBPs acted redundantly. For instance, Litc07A12770 was redundant to Litc07A12780 and Litc.07B14710 was redundant to Litc.07B14720. The genes with identical expression patterns were expressed at rates at least four times higher than other genes in the leaves of spring shoots. The emergence of these redundant genes may enable plants to precisely regulate the signaling pathway or rapidly adapt to a new environment (Wang et al. 2019).

TFs can regulate the expression of downstream genes in particular tissues by binding the cis-elements and transelements in the promoters ( $\mathrm{Li}$ et al. 2015). Previous reports suggested that AP2/EREBP TFs had a certain feedback regulation for a string of complicated processes, such as the development and senescence of seeds, flowers, leaves, and other organs and responses to cold, salt, drought, low temperature, and pathogens (Fujita et al. 2011; Guo et al. 2016; Phukan et al. 2017; Wang et al. 2019). RNA-sequencing data identified the higher expression of only 59 AP2/ERF genes in this study. About $88 \%$ of AP2/EREBP TFs expressed in 10 litchi tissues suggesting that AP2/EREBP genes have a broad regulatory network at the transcriptional level. The expression quantity or pattern of paralogous genes is not uniform specificity within the same organ, which may help to meet the different developmental needs of the inner and outer tissues of specific organs, such as leaves or roots. One of the main objectives of this study was to ascertain potential AP2/EREBP TFs involved in the somatic embryogenesis of litchi. The analyses of RNA-seq revealed that seven AP2 subfamily genes had upregulated expressions in the callus and somatic embryo, i.e. AP2-like genes (litc.06A13500 and 06B011950), BBM-like genes (litc.04A023400 and litc.05A002370), ANT-like genes (litc.04A022050), AIL5likes (litc.02A020200 and litc.02B020800), and PLT2-likes (litc.11A007580 and litc.11B005220). However, there have been no studies on how to induce the development and differentiation of litchi somatic embryos at higher AP2 protein quantities. Therefore, it is necessary to study the interaction functions of proteins encoded by litchi AP2/EREBP genes.

We performed further analysis by constructing protein interaction networks between litchi and Arabidopsis. In total, 46 AP2/EREBP genes showed interactions with other genes in the litchi genome. Considering the relationship between the structure and function of some essential proteins, the litchi AP2/EREBP factors sharing a higher identity with Arabidopsis AP2/EREBP proteins were perceived as having the same function. Protein-protein networks indicated that ERF and DREB proteins connected with $M P K 3 / M P K 6$ proteins, which have been reported to regulate freezing tolerance and stability in Arabidopsis by cascade action (Su et al. 2017), and the WRKY33 and ICE1 were their downstream TFs. Beyond that, they were coordinated with AP2 protein to involve a more powerful cross-linking network, which was determined to relate to plant growth and defense following the homologous gene annotations in Arabidopsis. RAVI interacted with TEMI to repress the transcription of floral regulators. These genes (RAV1, RAV2, and TEM1) may be involved in developmental adaptation in response to different environmental stimuli (Matías-Hernández et al. 2014). It is worth noting that BBM proteins modulated the process of somatic embryogenesis by binding and transcriptionally activating LEC1, LEC2, PLT2, and AIL5 as well as another positive regulator (Florez et al. 2015). The BBM-like genes (litc.04A023400 and litc.05A002370), PLT2-like genes (litc.11A007580 and litc.11B005220), and AIL5-like genes (litc.02A020200 and litc.02B020800) could be considered as candidates for further studies on their performance in facilitating litchi somatic embryogenesis. The above results indicated that litchi AP2/EREBP proteins were the junction point of regulating plant development and responding to biotic and abiotic stimulus by signal transduction. These findings provided new insight into transgenic technology to improve litchi yield and variety based on inducing embryogenesis and resisting adverse conditions.

In the current study, we identified 202 AP2/EREBP genes from the Litchi chinensis Sonn. genome. The exon-intron structure, conserved motif combination, and distribution of the chromosomes of these litchi AP2/ EREBPs were analyzed and compared. Litchi AP2/ EREBPs were divided into four subfamilies with regard to the number of AP2/EREBP domains and probabilistic functions. Studying the gene expression of litchi AP2/ EREBP genes in 10 tissues revealed that 59 genes were broadly involved in the regulation of plant tissue development. In particular, six genes may be major candidates involved in the regulation of litchi somatic embryogenesis. This study provides a comprehensive insight into the member organization, gene structure, gene evolution, gene expression, and protein interaction of the litchi AP2/EREREBP family factors. Furthermore, these embryogenesisrelated AP2/EREBP genes could be isolated and used in molecular breeding to improve litchi yield.

Supplementary Information The online version contains supplementary material available at https://doi.org/10.1007/s12042-021-09297-0.

Acknowledgements The authors acknowledge the funding from the Key Research and Development Plan for China-Modern Agriculture in Hainan Province (ZDYF2018044) and Chinese Modern Agricultural Industry Technology System (CARS-32-03) provided for this research. 
The authors are very grateful for the Chinese Academy of Tropical Agricultural Sciences Environment and Plant Protection Institute for offering lab and experimental materials.

Funding This work was supported by the Key Research and Development Plan for China-Modern Agriculture in Hainan Province (No. ZDYF2018044), Chinese Modern Agricultural Industry Technology System (No. CARS-32-03).

\section{Declarations}

Conflicts of Interest No potential conflicts of interest were disclosed.

Open Access This article is licensed under a Creative Commons Attribution 4.0 International License, which permits use, sharing, adaptation, distribution and reproduction in any medium or format, as long as you give appropriate credit to the original author(s) and the source, provide a link to the Creative Commons licence, and indicate if changes were made. The images or other third party material in this article are included in the article's Creative Commons licence, unless indicated otherwise in a credit line to the material. If material is not included in the article's Creative Commons licence and your intended use is not permitted by statutory regulation or exceeds the permitted use, you will need to obtain permission directly from the copyright holder. To view a copy of this licence, visit http://creativecommons.org/licenses/by/4.0/.

\section{References}

Chen C, Chen H, Zhang Y, Thomas HR, Frank MH, He Y, Xia R (2020) TBtools: an integrative toolkit developed for interactive analyses of big biological data. Mol Plant 13:1194-1202. https:// doi.org/10.1016/j.molp.2020.06.009

Chen H, Ou L, Li J, Su Z, Yang S, Wu Z, Hu Z (2019) Fruit scientific research in new China in the past 70 years: litchi. J Fruit Sci 36(10):1399-1433. https://doi.org/10.13925/j.cnki.gsxb.Z14

Chen L, Han J, Deng X, Tan S, Li L, Li L, Zhou J, Peng H, Yang G, He G, Zhang W (2016) Expansion and stress responses of AP2/EREBP superfamily in Brachypodium Distachyon. Sci Rep 6:21623. https://doi.org/10.1038/srep21623

Chen L, Hu W, Tan S, Wang M, Ma Z, Zhou S, Deng X, Zhang Y, Huang C, Yang G, He G (2012) Genome-wide identification and analysis of MAPK and MAPKK gene families in Brachypodium distachyon. PLoS One 7(10):e46744. https://doi.org/10.1371/journal.pone.0046744

Cline MS et al (2007) Integration of biological networks and gene expression data using cytoscape. Nat Protoc 2(10):2366-2382. https://doi.org/10.1038/nprot.2007.324

Corpet $\mathrm{F}$ (1988) Multiple sequence alignment with hierarchical clustering. Nucleic Acids Res 16(12):10561-10573. https://doi.org/10. 1093/nar/16.22.10881

Dossa K, Wei X, Li D, Fonceka D, Zhang Y, Wang L, Yu J, Boshou L, Diouf D, Cissé N, Zhang X (2016) Insight into the AP2/ERF transcription factor superfamily in sesame and expression profiling of DREB subfamily under drought stress. BMC Plant Biol 16:171. https://doi.org/10.1186/s12870-016-0859-4

Du H, Yang SS, Liang Z, Feng BR, Liu L, Huang YB, Tang YX (2012) Genome-wide analysis of the MYB transcription factor superfamily in soybean. BMC Plant Biol 12:106. https://doi.org/10.1186/ 1471-2229-12-106

Fan ZQ, Kuang JF, Lu WJ, Chen JY (2015) Advances in research of the mechanism of transcription factors involving in regulating fruit ripening and senescence. Acta Hortic Sin 42(9):1649-1663. https://doi.org/10.16420/j.issn.0513-353x.2015-0356 (in chinese)

Finn RD, Clements J, Eddy SR (2011) HMMER web server: interactive sequence similarity searching. Nucleic Acids Res 39:29-37. https://doi.org/10.1093/nar/gkr367

Florez SL, Erwin RL, Maximova SN, Guiltinan MJ, Curtis WR (2015) Enhanced somatic embryogenesis in Theobroma cacao using the homologous $B A B Y B O O M$ transcription factor. BMC Plant Biol 15:121. https://doi.org/10.1186/s12870-015-0479-4

Fujita Y, Fujita M, Shinozaki K, Yamaguchi-Shinozaki K (2011) ABA-mediated transcriptional regulation in response to osmotic stress in plants. J Plant Res 124(4):509-525. https://doi.org/10. 1007/s10265-011-0412-3

Giri MK, Swain S, Gautam JK, Singh S, Singh N, Bhattacharjee L, Nandi AK (2014) The Arabidopsis thaliana At4g13040 gene, a unique member of the AP2/EREBP family, is a positive regulator for salicylic acid accumulation and basal defense against bacterial pathogens. J Plant Physiol 171(10):860-867. https:// doi.org/10.1016/j.jplph.2013.12.015

Gou Y, Zhang L, Guo H, Ma H, Bao A (2020) Research progress on the AP2/ERF transcription factor in plants. Pritacultural Sci 37(6):1150 1159. https://doi.org/10.11829/j.issn.1001-0629.2019-0440

Guo B, Wei Y, Xu R, Lin S, Luan H, Lv C, Zhang X, Song X, $\mathrm{Xu} \mathrm{R}$ (2016) Genome-wide analysis of APETALA2/ethyleneresponsive factor (AP2/ERF) gene family in barley (Hordeum vulgare L.). PLoS One 11(9):1-17. https://doi.org/10.1371/ journal.pone.0161322

Holub EB (2001) The arms race is ancient history in Arabidopsis, the wildflower. Nat Rev Genet 2(7):516-527. https://doi.org/ $10.1038 / 35080508$

Hu L, Liu S (2011) Genome-wide identification and phylogenetic analysis of the ERF gene family in cucumbers. Genet Mol Biol 34(4):624 633. https://doi.org/10.1590/S1415-47572011005000054

Jiang C, Iu B, Singh J (1996) Requirement of a CCGAC cis-acting element for cold induction of the BN115 gene from winter Brassica napus. Plant Mol Biol 30(3):679-684. https://doi.org/10. 1007/bf00049344

Jin JH, Min W, Zhang HX, Khan A, Wei AM, Luo DX, Gong ZH (2018) Genome-wide identification of the AP2/ERF transcription factor family in pepper (Capsicum annuиm L.). Genome 61(9):663-674. https://doi.org/10.1139/gen-2018-0036

Khaksefidi RE, Mirlohi S, Khalajin F, Fakharin Z, Shiran B, Fallahi H, Rafiei F, Budak H, Ebrahimie E (2015) Differential expression of seven conserved microRNAs in response to abiotic stress and their regulatory network in Helianthus annuus. Front Plant Sci 6(747). https://doi.org/10.3389/fpls.2015.00741

Kumar K, Muthamilarasan M, Prasad M (2013) Reference genes for quantitative real-time PCR analysis in the model plant foxtail millet (Setaria italica L.) subjected to abiotic stress conditions. Plant Cell Tissue Organ Cult 115(1):13-22. https://doi.org/10. 1007/s11240-013-0335-x

Lata C, Mishra AK, Muthamilarasan M, Bonthala VS, Khan Y, Prasad M (2014) Genome-wide investigation and expression profiling of AP2/ERF transcription factor superfamily in Foxtail Millet (Setaria italica L). PLoS One 9(11):e113092. https://doi. org/10.1371/journal.pone.0113092

Lata C, Sahu PP, Prasad M (2010) Genome-wide investigation and expression profiling of AP2/ERF transcription factor superfamily in foxtail millet (Setaria italica L.). PLoS One, 9:e113092. https://doi.org/10.1016/j.bbrc.2010.02.068

Li MY, Xu ZS, Huang Y, Tian C, Wang F, Xiong AS (2015) Genome-wide analysis of AP2/ERF transcription factors in carrot (Daucus carota L.) reveals evolution and expression profiles under abiotic stress. MolGenet Genomics 290(6):2049-2061. https://doi.org/10.1007/s00438-015-1061-3 
Li X, Tao S, Wei S, Ming M, Huang X, Zhang S, Wu J (2018) The mining and evolutionary investigation of AP2/ERF genes in pear (Pyrus). BMC Plant Biol 18:46. https://doi.org/10.1186/ s12870-018-1265-x

Li X, Zhang D, Gao B, Liang Y, Yang H, Wang Y, Wood AJ (2017) Transcriptome-wide identification, classification, and characterization of AP2/ERF family genes in the desert moss syntrichia caninervis. Front Plant Sci 8:262. https://doi.org/10.3389/ fpls.2017.00262

Licausi F, Giorgi FM, Zenoni S, Osti F, Pezzotti M, Perata P (2010) Genomic and transcriptomic analysis of the AP2/ERF superfamily in Vitis vinifera. BMC Genomics 11(1):719. https://doi.org/ 10.1186/1471-2164-11-719

Liu C, Zhang T (2017) Expansion and stress responses of the AP2/ EREBP superfamily in cotton. BMC Genomics 18:118. https:// doi.org/10.1186/s12864-017-3517-9

Livak KJ, Schmittgen TD (2001) Analysis of relative gene expression data using real-time quantitative PCR and the $2^{-\Delta \Delta C T}$ method. Methods 25(4):402-408. https://doi.org/10.1006/meth.2001.1262

Matías-Hernández L, Aguilar-Jaramillo AE, Marín-González E, Suárez-López P, Pelaz S (2014) RAV genes: regulation of floral induction and beyond. Ann Bot 114(7):1459-1470. https://doi. org/10.1093/aob/mcu069

Nakano T, Suzuki K, Fujimura T, Shinshi H (2006) Genome-wide analysis of the ERF gene family in Arabidopsis and rice. Plant Physiol 140:411-432. https://doi.org/10.1104/pp.105.073783

Phukan UJ, Jeena GS, Tripathi V, Shukla RK (2017) Regulation of Apetala2/Ethylene response factors in plants. Front Plant Sci 8:150. https://doi.org/10.3389/fpls.2017.00150

Reams AB, Neidle EL (2004) Selection for gene clustering by tandem duplication. Annu Rev Microbiol 58:119-142. https://doi.org/10. 1146/annurev.micro.58.030603.123806

Sakuma Y, Liu Q, Dubouzet JG, Abe H, Yamaguchi-Shinozaki K, Shinozaki K (2002) DNA-binding specificity of the ERF/AP2 domain of Arabidopsis DREBs, transcription factors involved in dehydration- and cold-inducible gene expression. Biochem Biophys Res Commun 290:998-1009. https://doi.org/10.1006/ bbrc.2001.6299

Shu Y, Liu Y, Zhang J, Song L, Guo C (2016) Genome-wide analysis of the AP2/ERF superfamily genes and their responses to abiotic stress in Medicago truncatula. Front Plant Sci 6:1247. https://doi. org/10.3389/fpls.2015.01247
Song X, Wang J, Ma X, Li Y, Lei T, Wang L, Ge W, Guo D, Wang Z, Li C, Zhao J, Wang X (2016) Origination, expansion, evolutionary trajectory, and expression bias of AP2/ERF superfamily in Brassica napus. Front Plant Sci 7:1186. https://doi.org/10.3389/ fpls.2016.01186

Su J, Zhang M, Zhang L, Sun T, Liu Y, Lukowitz W, Xu J, Zhang S (2017) Regulation of stomatal immunity by interdependent functions of a pathogen-responsive MPK3/MPK6 cascade and abscisic acid. Plant Cell 29(3):526-542. https://doi.org/10.1105/ tpc. 16.00577

Tang Y, Qin S, Guo Y, Chen Y, Wu P, Chen Y, Li M, Jiang H, Wu G (2016) Genome-wide analysis of the AP2/ERF gene family in physic nut and overexpression of the JCERF011 gene in rice increased its sensitivity to salinity stress. PLoS One 11:1-20. https://doi.org/10.1371/journal.pone.0150879

Taylor JS, Raes J (2004) Duplication and divergence: the evolution of new genes and old ideas. Annu Rev Genet 38:615-643. https:// doi.org/10.1146/annurev.genet.38.072902.092831

Thompson JD, Higgins DG, Gibson TJ (1994) CLUSTAL W: improving the sensitivity of progressive multiple sequence alignment through sequence weighting, position-specific gap penalties and weight matrix choice. Nucleic Acids Res 22(22):4673-4680. https://doi.org/10.1093/nar/22.22.4673

Trifinopoulos J, Nguyen LT, von Haeseler A, Minh BQ (2016) W-IQTREE: a fast online phylogenetic tool for maximum likelihood analysis. Nucleic Acids Res 44(W1):W232-W235. https://doi.org/ $10.1093 / \mathrm{nar} / \mathrm{gkw} 256$

Wang G (2013) Studies on regeneration of three Litchi (Litchi chinensis Sonn.) cultivars in vitro. (in chinese)

Wang L, Ma H, Lin J (2019) Angiosperm-wide and family-level analyses of AP2/ERF genes reveal differential retention and sequence divergence after whole genome duplication. Front Plant Sci 10:196. https://doi.org/10.3389/fpls.2019.00196

$\mathrm{Xu}$ W, Li F, Ling L, Liu A (2013) Genome-wide survey and expression profiles of the AP2/ERF family in castor bean (Ricinus communis L.). BMC Genomics 14(1): 785. https://doi.org/10.1186/ 1471-2164-14-785

Publisher's Note Springer Nature remains neutral with regard to jurisdictional claims in published maps and institutional affiliations. 